\title{
What we don't (but should) teach young researchers
}

\author{
Archie L Dick \\ University of Pretoria
}

\begin{abstract}
Emotions in research remain largely unaddressed. One reason is that we are beholden to a narrow social scientific conception of LIS (library and information science). By teaching young researchers where and how emotions operate in all phases of the research process we will discover some unexpected insights.
\end{abstract}

Keywords

Emotions, research methodology, social science.

Corresponding author

Archie L Dick, Professor, Department of Information Science, University of Pretoria, Lynnwood Road, Pretoria, Republic of South Africa, 0002. archie.dick@up.ac.za

A few years ago I received a disturbing telephone call from a former colleague. I had already interviewed him a few years earlier and he now wanted to share more recollections about his life and library career. What struck me was the urgency for us to meet as soon as possible, and the remark that he was suffering from cancer and did not have much time left. When we met I struggled between objectivity and a deep sadness as I spoke with and recorded him. Sadly, he passed away not long afterwards.

During a different interview, a feeling of disgust threatened my objectivity. I had asked a former librarian who during a period of book burning 
in the apartheid era was quoted by a newspaper journalist about the fate of banned books collected from branch libraries and brought to the Central Library, as follows: 'Then we will have a big bonfire and burn them' (New list, 1957: 6). When I asked him whether or not this was true he replied calmly that he had absolutely no recollection of that period of his career.

How do researchers deal responsibly with these and other emotions? What methodological technique is there in the researcher's tool kit to deal with them? Sometimes explicitly and sometimes subtly, research methodology textbooks and courses tell us to banish emotions as factors that flaw research. And yet, research can often be or become an emotionally-charged activity. How do we prepare young researchers for a sudden and unexpected turn of events during an interview, like an emotional breakdown by an interviewee or the potential psychological meltdown of an interviewer overwhelmed by empathy? Should they dismiss or acknowledge feelings that entangle the research process in several of its phases?

One source of this difficulty involves our research traditions, canons and protocols of methodology, but another is about how we think about our discipline and about ourselves. In the attempt to become a respectable academic discipline worthy of inclusion in university-based degree programmes, LIS sought a social scientific status that adopted the ideals of classic liberalism, which emphasize value neutrality and objectivity. In its preference for this path to achieve scientific status, LIS effectively dismissed emotions, subjectivity, and disputes about moral values (Dick, 1995).

There has, however, always been more than one way for LIS to become a social science. In brief, alternative approaches emphasize a 
connection between social scientific inquiry and the pursuit of the human good that questions a strict separation between researchers and the object of research, as well as the degree of participation by ordinary people and ordinary human experience in research. Even at the heart of the most extreme form of empiricism, which is called logical positivism, there is a contradiction for the so-called value free and objective social sciences. It is that classical empiricists are empirical about everything except the concept of ‘experience’ itself as a source of knowledge (Dick, 1991; 1993).

Emotions are an important part of human experience as a source of knowledge (Turner \& Stets, 2005). They cannot simply be ignored or dismissed. Emotions affect the research process 'in terms of what is studied or not studied, by whom and in what way, but they may also influence researchers' interpretations and readings of a situation' (Widdowfield, 2000: 199). We should teach young researchers how to deal with emotions, and we can start by recognizing that emotions in research operate on at least three levels.

At the first level, and especially in interview-based research, there are emotions involved in the relations between researcher and interviewee, or respondent. We are now aware, especially through in-depth interviewing, that ethical issues surface when we tap into areas that are emotionally sensitive for respondents. Some of these emotional issues are managed through mechanisms such as ethics committees that scrutinize questionnaires and interview schedules to minimize potential personal offense taken by respondents. 
For the researcher, there are strategies for managing emotions especially in team research where sharing or opening up about sensitive issues with team members can help deal with emotional distress. Techniques such as pacing an interview, avoiding interviews at certain times of the day, or on certain days, note writing, and de-briefing sessions allow researchers to acknowledge and utilize emotional experiences instead of avoiding them (Cylwik, 2001; Hubbard et al, 2001).

At the second level are emotions involved in the relations between a researcher and the research topic, especially sensitive topics. In dealing with the information behaviour of vulnerable or socially excluded groups like HIVIAIDS patients, prostitutes, immigrants, victims of human trafficking and so forth there is often a greater concern for the protection of the research project and the integrity of the data than for the emotional vulnerability of the researcher.

We avoid certain topics or participation in research projects involving topics such HIVIAIDS or child abuse that anticipate emotional distress or discomfort. The affective paradigm in information behavior research has emerged in the past few years to address some of the emotional aspects of information seeking and sharing, but it fails to deal meaningfully with the feelings of the researcher.

At the third level are emotions involved in the relations between researchers and their own research experiences and feelings. This involves reflexiveness or self-evaluation in which researchers continuously draw on and assess their previous theoretical ideas and experiences, and re-create themselves in the process. In doing so, they acknowledge that research 
practice is not just about career and intellect, but also an emotional and personal journey. This continuous self-critical exercise allows researchers to confront the emotions that are present in their work, and as a result, to negotiate and manage them to improve the quality of future research (Burman, 2006; Hallowell et al, 2005).

Teaching young researchers where and how emotions operate in all phases of the research process foregrounds unexpected insights. Emotions affect the LIS researcher's decisions about which topics to investigate or leave to others. Emotions can be a mirror that reflects prejudices and takenfor-granted beliefs and assumptions. Emotions affect the mechanics of data gathering, and this data eventually becomes coded as findings and established knowledge in LIS.

By recognizing instead of ignoring emotions we experience research as not just a voyage of discovery about the world of LIS. It is also a voyage of self-discovery.

\section{References}

Burman, E (2006) Emotions and reflexivity in feminised education action research. Educational Action Research, 14(3): 315-32.

Cylwik, H (2001) Notes from the field: emotions of place in the production and interpretation of text. International Journal of Social Research Methodology, 4(3): 243-50.

Dick, A L (1991) The influence of positivism on the design of scientific techniques: implications for library and information science research. South African Journal for Library and Information Science, 59(4): 231-9. 
Dick, A L (1993) Three paths to inquiry in library and information science: positivist, constructivist and critical theory approaches. South African Journal of Library and Information Science, 61(2): 53-60.

Dick, A L (1995) Library and Information Science as a social science: neutral and normative conceptions. The Library Quarterly, 65(2): 216- 35.

Hallowell, N, Lawton, J \& Gregory, S (eds) (2005) Reflections on Research: The Realities of doing Research in the Social Sciences. Berkshire: Open University Press.

Hubbard, G, Backett-Milburn, K \& Kemmer, D (2001) Working with emotion: issues for the researcher in fieldwork and teamwork. International Journal of Social Research Methodology, 4(2): 119-37.

'New list of banned books includes Russian classics, Diana Dors', Cape Times, Tuesday, 8 October 1957: 6.

Turner, J H \& Stets, J E (2005) The Sociology of Emotions. Cambridge: Cambridge University Press.

Widdowfield, R (2000) The place of emotions in academic research. Area: 32(2): 199-208. 